05

\title{
Повышение прочностных характеристик титана при имплантации ионами аргона
}

\author{
(С) И.В. Перинская, И.В. Родионов, Л.Е. Куц , О.Д. Тищенко
}

Саратовский государственный технический университет им. Гагарина Ю.А., Саратов, Россия

`E-mail: kuts70@yandex.ru

Поступило в Редакцию 6 сентября 2017 г.

Исследовано влияние имплантации ионов аргона при ускоряющем напряжении $40-130 \mathrm{kV}$ в диапазоне доз $(1-4) \cdot 10^{16} \mathrm{ion} / \mathrm{cm}^{2}$ на морфологию, микротвердость и усталостную прочность титана. Предложен способ упрочнения и модификации поверхности титана ионами аргона $\left(\mathrm{Ar}^{+}\right)$, открывающий новые возможности его применения в электротехнических устройствах энергетического, химического и металлургического машиностроения.

DOI: 10.21883/PJTF.2018.10.46104.17030

Проблемы науки и технологии, связанные с методами поверхностной обработки конструкционных материалов, в частности титановых сплавов, подвергающихся воздействию агрессивных сред и применяемых в энергетическом, химическом и металлургическом машиностроении, стимулируют экспериментальные и теоретические исследования физических процессов, моделирование физических явлений при разработке новых технологических методик [1].

Для улучшения механических характеристик конструкционных материалов используется группа технологических методов: вакуумно-конденсационное напыление, микродуговое и термическое оксидирование, цементация, азотирование и другие методы формирования покрытий и функциональных слоев [2-6]. Однако каждый из этих методов недостаточно эффективен для изменения структуры поверхности, придания высокой усталостной прочности и коррозионной стойкости.

Одним из перспективных методов поверхностной обработки материалов, расширяющих возможности влияния на характеристики поверхности и приповерхностного слоя (глубиной до $100 \mathrm{~nm}$ ), является ионная имплантация. При этом актуальной научной задачей является 

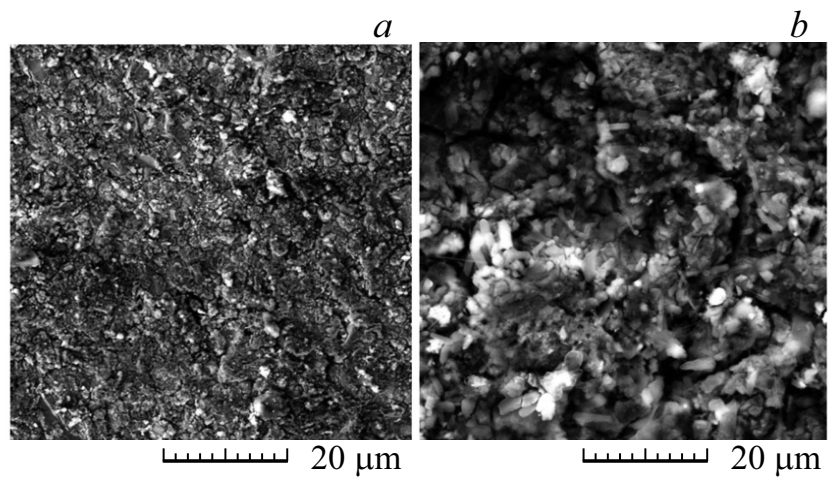

Рис. 1. Электронно-микроскопические изображения поверхности титана, модифицированного ионами аргона $\left(U_{a c c}=75 \mathrm{kV}\right) . \quad F=1.25 \cdot 10^{16}(a)$ и $3.2 \cdot 10^{16} \mathrm{ion} / \mathrm{cm}^{2}(b)$.

экспериментальное исследование и моделирование физических явлений, сопровождающих ионно-лучевую обработку поверхности титана ионами аргона $\left(\mathrm{Ar}^{+}\right)$в углеродсодержащей среде с целью создания на поверхности титана углеродсодержащего покрытия с повышенными механическими характеристиками. Таким образом, цель настоящей работы заключается в исследовании влияния процесса имплантации аргона на механические свойства поверхности титана в зависимости от ускоряющего напряжения и дозы ионов.

Экспериментальные образцы титана марки ВТ1-0 (ГОСТ 19807-91) представляли собой пластины размером $25 \times 20 \mathrm{~mm}$ с толщиной $2 \mathrm{~mm}$. Механически обработанная, полированная и химически отчищенная поверхность титановых образцов подвергалась ионно-лучевой обработке ионами аргона в среде углекислого газа при пониженном давлении $\left(\sim 10^{-3} \mathrm{~Pa}\right)$ на установке ионного легирования „Везувий-5“ при различных режимах ускоряющего напряжения $U_{a c c}$ и дозах имплантации ионов $F$.

Микротвердость поверхности измерялась методом вдавливания алмазного индентора на твердомере HVS-1000B при нагрузке $20 \mathrm{gf}$ в течение $15 \mathrm{~s}$ (ГОСТ 2999-75). Испытания на усталостную прочность проводились по схеме консольного изгиба до разрушения. При этом максимальное изгибающее напряжение по сечению образца находилось

7 Письма в ЖТФ, 2018, том 44, вып. 10 
Таблица 1. Данные ВИМС по количественному содержанию углерода и углеродсодержащих фаз в модифицированном слое титана

\begin{tabular}{c|c|c|c}
\hline \multirow{2}{*}{$\begin{array}{c}\text { Элемент, } \\
\text { соединение }\end{array}$} & \multirow{2}{*}{ Масса, u } & \multicolumn{2}{|c}{ Содержание, rel. un. } \\
\cline { 3 - 4 } & & Исходная поверхность & $\begin{array}{c}\text { Модифицированная } \\
\text { поверхность }\end{array}$ \\
\hline $\mathrm{C}$ & 12 & 500 & 600 \\
$\mathrm{CH}$ & 13 & $5 \cdot 10^{4}$ & $5 \cdot 10^{4}$ \\
$\mathrm{CH}_{2}$ & 14 & 190 & 230 \\
$\mathrm{CH}_{4}$ & 16 & 180 & 220 \\
$\mathrm{CO}$ & 28 & 1600 & 4700 \\
$\mathrm{CO}_{2}$ & 44 & 250 & 750
\end{tabular}

в интервале значений 240-450 МРа при частоте цикла нагрузки $22.5 \mathrm{~Hz}$ (ГОСТ 25.502-79).

Морфологические изменения фиксировались с помощью растрового электронного микроскопа с холоднополевой эмиссией JSM-6701F (ускоряющее напряжение $0.5-30 \mathrm{kV})$.

Электронно-микроскопические исследования показали, что при дозах $\sim 1.25 \cdot 10^{16} \mathrm{ion} / \mathrm{cm}^{2}$ поверхность титана сохраняет вид, характерный для необлученных образцов (рис. $1, a$ ). При дозе $3.2 \cdot 10^{16} \mathrm{ion} / \mathrm{cm}^{2}$, соответствующей химической пассивации, на его поверхности возникали вытянутые ориентированные образования, система которых схожа с дендритной (рис. $1, b)$.

Исследование химического состава поверхностных слоев методом вторично-ионной масс-спектрометрии (ВИМС) показывает повышение концентрации углерода на поверхности и в приповерхностном слое титана (табл. 1).

Изменение морфологии и химического состава поверхности титановых образцов после модифицирующей обработки в среде углекислого газа при пониженном давлении в диапазоне экспериментально полученных доз ионов $\mathrm{Ar}^{+}(1.25-3.2) \cdot 10^{16} \mathrm{ion} / \mathrm{cm}^{2}$ с ускоряющим напряжением $40-130 \mathrm{kV}$ свидетельствует о формировании на ней углеродсодержащей беспористой пленки.

Предлагаемый механизм формирования на титановой поверхности углеродсодержащей беспористой пленки связан с полимеризацией ато-

Письма в ЖТФ, 2018, том 44, вып. 10 


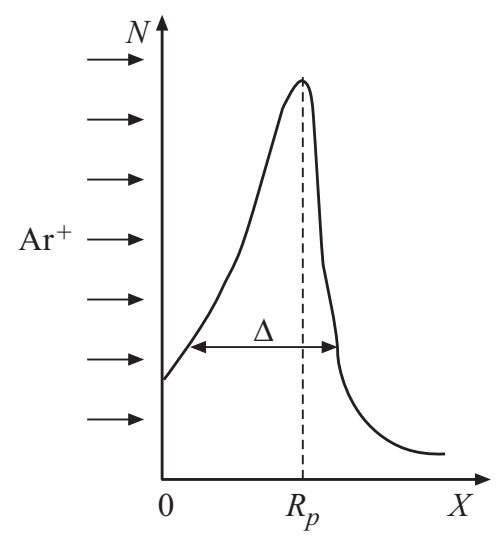

Рис. 2. Профиль распределения имплантируемых ионов $\mathrm{Ar}^{+}$в слое металла. $R_{p}$ - проецируемый пробег ионов.

мов углерода углекислого газа, дозированно вводимого в приемную камеру.

При энергетическом воздействии имплантируемых ионов аргона в углеродсодержащей среде в поверхностном слое адсорбированных фрагментов происходят процессы диссоциации и ионизации молекул. Это приводит к возникновению заряженных радикалов, синтез которых стимулируется энергетическим воздействием внедряемых ионов аргона с характерным профилем распределения и контролируется поступлением электронов из нижележащего металла (рис. 2). По мере увеличения толщины синтезируемого слоя поступление электронов к поверхности затрудняется, и при достижении толщины порядка длины туннелирования электронов рост углеродсодержащей пленки прекращается (рис. 3).

Наиболее интенсивно процесс синтеза протекает на участках слоя с меньшей толщиной и порами, что обеспечивает высокую равномерность беспористой пленки.

Одновременно с формированием углеродсодержащей беспористой пленки повышается структурная равномерность имплантированной ионами аргона поверхности титана. Структура исходных слоев титана в виде разупорядоченных поликристаллов в процессе ионно-лучевой обработки проходит стадии уменьшения размера зерна вплоть до воз-

7* Письма в ЖТФ, 2018, том 44, вып. 10 


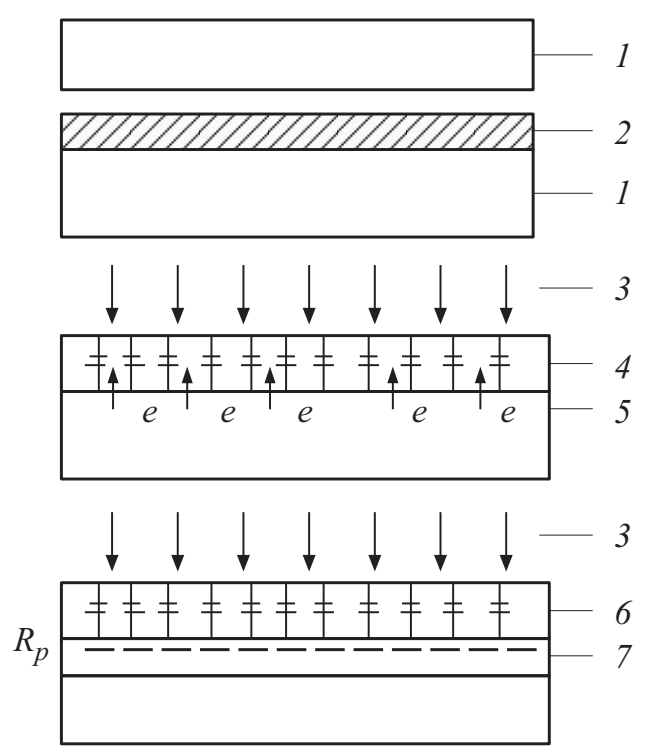

Рис. 3. Схема формирования на поверхности титана углеродсодержащей беспористой пленки в процессе ионно-лучевого модифицирования: 1 - титан, 2 - углеродные адсорбированные фрагменты, 3 - ионы аргона, 4 - сшивка мономеров (адсорбированных фрагментов), 5 - электроны; $6-$ углеродсодержащая беспористая пленка; 7 - область объемных структурных изменений в титане.

никновения аморфной фазы, последующего зарождения поликристаллических включений, увеличения их концентрации. Ионы аргона, образуя с дефектами устойчивые кластеры, стабилизируют метастабильную фазу [7].

Изменение прочностных характеристик модифицированных аргоном образцов титана имеет зависимость от дозы при ионно-лучевой обработке. Установлено, что при дозах ионов аргона менее $1.25 \cdot 10^{16} \mathrm{ion} / \mathrm{cm}^{2}$ и более $3.2 \cdot 10^{16} \mathrm{ion} / \mathrm{cm}^{2}$ не происходит формирования углеродсодержащей беспористой пленки на поверхности титановой основы образцов, снижаются микротвердость и усталостная прочность имплантированного ионами аргона титана в среде углекислого газа, что подтверждается результатами исследования (табл. 2).

Письма в ЖТФ, 2018, том 44, вып. 10 
Таблица 2. Зависимость значений микротвердости и усталостной прочности поверхности титана от ускоряющего напряжения и дозы имплантированных ионов аргона

\begin{tabular}{|c|c|c|c|c|}
\hline $\begin{array}{c}\text { № } \\
\text { П/ா }\end{array}$ & $\begin{array}{c}\text { Ускоряющее } \\
\text { напряжение } \\
\text { ионов } \mathrm{Ar}^{+}, \mathrm{kV}\end{array}$ & $\begin{array}{c}\text { Доза ионов } \\
\mathrm{Ar}^{+}, \\
10^{16} \text { ion } / \mathrm{cm}^{2}\end{array}$ & $\begin{array}{c}\text { Микротвердость } \\
H, \\
\mathrm{kgf} / \mathrm{mm}^{2}\end{array}$ & $\begin{array}{c}\text { Усталостная } \\
\text { прочность } \\
\sigma_{\max }, \mathrm{MPa}\end{array}$ \\
\hline 1 & - & - & 230 & 350 \\
\hline 2 & 40 & 0.18 & 260 & 350 \\
\hline 3 & 40 & 1.25 & 310 & 400 \\
\hline 4 & 40 & 2 & 335 & 450 \\
\hline 5 & 40 & 2.5 & 330 & 450 \\
\hline 6 & 40 & 3.2 & 310 & 450 \\
\hline 7 & 40 & 4 & 250 & 420 \\
\hline 8 & 130 & 1.8 & 260 & 400 \\
\hline 9 & 130 & 1.25 & 325 & 450 \\
\hline 10 & 130 & 2 & 340 & 450 \\
\hline 11 & 130 & 2.5 & 340 & 450 \\
\hline 12 & 130 & 3.2 & 325 & 450 \\
\hline 13 & 130 & 4 & 265 & 440 \\
\hline
\end{tabular}

Максимальное увеличение микротвердости поверхности титана марки ВТ1-0 на 25-30\% наблюдается при дозе имплантируемых ионов аргона $(1.25-3.2) \cdot 10^{16} \mathrm{ion} / \mathrm{cm}^{2}$, что может быть связано с образованием радиационных дефектов. Максимальное повышение усталостной прочности достигается при той же дозе имплантации ионов $\mathrm{Ar}^{+}$, при которой имеет место максимум зависимости микротвердости от дозы, и практически не зависит от ускоряющего напряжения ионов аргона $\mathrm{Ar}^{+}$ в исследуемом диапазоне (табл. 2).

Таким образом, установлено, что применение ионной имплантации аргона $\left(\mathrm{Ar}^{+}\right)$позволяет повысить микротвердость и усталостную прочность титана. Установлен эффект формирования углеродсодержащей беспористой пленки на поверхности титана при имплантации ионов аргона с ускоряющим напряжением $U_{a c c}=40-130 \mathrm{kV}$ и дозой $F=(1-4) \cdot 10^{16} \mathrm{ion} / \mathrm{cm}^{2}$ в среде углекислого газа. Ионная имплантация аргона в среде углекислого газа приводит к увеличению микротвердости поверхности титана ВТ1-0 на 25-30\%, причем максимум достигается в

Письма в ЖТФ, 2018, том 44, вып. 10 
диапазоне доз ионов $(1.25-3.2) \cdot 10^{16} \mathrm{ion} / \mathrm{cm}^{2}$. Усталостная прочность образцов титана зависит от дозы имплантированных ионов аргона в среде углекислого газа и имеет наибольшее значение при дозах облучения $(2.0-3.2) \cdot 10^{16} \mathrm{ion} / \mathrm{cm}^{2}$ с $U_{a c c}=40 \mathrm{kV}$ и $(1.25-3.2) \cdot 10^{16} \mathrm{ion} / \mathrm{cm}^{2} \mathrm{c}$ $U_{a c c}=130 \mathrm{kV}$.

Исследования выполнены при финансовой поддержке Минобрнауки РФ в рамках государственного задания образовательным организациям высшего образования, подведомственным Минобрнауки РФ (проект 11.1943.2017/4.6).

\section{Список литературы}

[1] Калита В.И., Бочарова М.А., Трушникова А.С., Шатерников Б.Н. // Металлы. 2005. № 3. С. 105-110.

[2] Нечаев Г.Г., Кошуро В.А. // Физика и химия обраб. материалов. 2015. № 5. C. 29-34.

[3] Fomin A.A., Dorozhkin S.V., Fomina M.A., Koshuro V.A., Rodionov I.V., Zakharevich A.M., Petrova N., Skaptsov A.A. // Ceram. Int. 2016. V. 42. N 9. P. $10838-10846$.

[4] Pham V.-H., Lee S.-H., Li Y., Kim H.-E., Shin K.-H., Koh Y.-H. // Thin Solid Films. 2013. V. 536. P. 269-274.

[5] Rodionov I.V. // Met. Sci. Heat Treatment. 2014. V. 55. N 11-12. P. 599-602.

[6] Фомин А.А., Фомина М.А., Родионов И.В., Кошуро В.А., Пошивалова Е.Ю., Щелкунов А.Ю., Скапцов А.А., Захаревич А.М., Аткин В.С. // Письма в ЖТФ. 2015. Т. 41. В. 18. С. 89-95.

[7] Перинская И.В., Лясников В.Н. // Перспективные материалы. 2009. № 5. C. 45-49. 